\title{
ANTIGENIC VARIATIONS IN THE SEMINAL PLASMA OF DIFFERENT MEN
}

\author{
SALLY DEFAZIO, B. K. LEWIS AND M. M. KETCHEL \\ Department of Physiology, Tufts University School of Medicine, \\ Boston, Mass., U.S.A.
}

(Received 2nd August 1968)

\begin{abstract}
Summary. Immuno-electrophoretic analysis of human seminal plasma reveals minor but distinct differences in the antigenic components when the seminal plasma is obtained from different individuals. These differences exist primarily in those proteins of seminal plasma which do not occur in the blood, and are independent of $\mathrm{ABO}$ secretor status. The failure to detect some antigens in the seminal plasma of some individuals may be due not to their absence but to their low concentrations. Examination of several successive ejaculates collected within $\frac{1}{2}$ to $2 \mathrm{hr}$ from each of three donors indicated that variations were interindividual rather than intra-individual in nature.
\end{abstract}

\section{INTRODUCTION}

Seminal plasma contains a number of different proteins, some of which occur in the blood and some of which do not (Hermann, Licht, Keutel \& Krug, 1958; Rao \& Sadri, 1959; Mischler \& Reineke, 1966; Behrman \& Amano, 1967). These proteins are highly antigenic when injected into an animal of a different species, but not when injected into an animal of the same species (Menzoian \& Ketchel, 1966). The members of a single species, therefore, appear to be immunologically tolerant to the seminal plasma proteins of that species, just as they are to the blood plasma proteins. Menzoian \& Ketchel (1966) demonstrated that the female reproductive tract shares with the male some protein or proteins which do not occur in the blood or certain tissues. It was suggested that the female acquires immunological tolerance to seminal plasma proteins by producing the same proteins in those accessory glands of the female reproductive tract which are embryological homologues of the male accessory glands.

The immunological tolerance of the female seems to extend to all of the proteins which occur in the seminal plasma of virtually all males of the species. Reports of serious immunological reactions to insemination are rare (Halpern, Ky \& Robert, 1967), even though repeated inseminations of women by men who have very different genetic backgrounds is a frequent occurrence. Since the number of proteins to which females are tolerant must be limited, no appreciable variation would be expected in the antigens represented in the seminal plasma among the males of a single species. The present experiments 
were designed to determine the degree to which normal men differ in the antigens contained in their seminal plasma. Data are also presented concerning the variation which exists in the antigens present in different ejaculates from the same individual.

\section{MATERIALS AND METHODS}

Five healthy young men (Donors $A$ to $E$ ) each provided a series of semen samples. Each sample was obtained following a 3-day continence. Three additional donors ( $\mathbf{F}$ to $\mathrm{H}$ ) each provided three ejaculates collected within $\frac{1}{2}$ to $2 \mathrm{hr}$, and a fourth ejaculate obtained 14 days or more later. The volumes collected in each sample, and the time which elapsed between the first and third and the first and fourth samples for Donors F, G and $\mathrm{H}$ are shown in Table 1. All semen samples were quickly centrifuged to remove spermatozoa and detritus, and were immediately frozen and stored at $-30^{\circ} \mathrm{C}$ until use.

Immunological experiments usually utilize antisera pooled from a number of animals, and antigen pooled from a number of donors. The rationale for pooling antisera from a number of animals stems from the observation that a

TABle 1

CONSECUTIVE EJACULATES FROM THREE DONORS

\begin{tabular}{c|c|c|c|c|c|c}
\hline \multirow{2}{*}{ Donor } & \multicolumn{3}{|c|}{ Volume of consecutive ejaculates $(\mathrm{ml})$} & \multicolumn{2}{|c}{ Time between collection of: } \\
\cline { 2 - 7 } & First & Second & Third & Fourth & First and third samples & First and fourth samples \\
\hline F & $2 \cdot 4$ & $0 \cdot 6$ & $0 \cdot 35$ & 1.4 & $60 \mathrm{~min}$ & 14 days \\
G & $>1 \cdot 8$ & $1 \cdot 3$ & $0 \cdot 3$ & 6.9 & $30 \mathrm{~min}$ & 14 days \\
H & $3 \cdot 0$ & $2 \cdot 0$ & $1 \cdot 8$ & $2 \cdot 0$ & $120 \mathrm{~min}$ & 20 days \\
\hline
\end{tabular}

single animal will not usually respond maximally to each antigen in a mixture of antigens. We injected only one rabbit with seminal plasma from each donor. Cross-checking each donor's seminal plasma with antiserum from each immunized rabbit provided information concerning which antigens had or had not elicited antibody formation in any one rabbit. Two antisera were relatively complete. While neither contained all of the antibodies detected in this study, all of the antibodies detected occurred in one or the other of these two antisera. Therefore, testing each donor's seminal plasma against these two antisera provided information concerning all of the known antigens.

In order to elicit a maximal response to the antigen of each donor, we did not pool seminal plasma from more than one donor for the immunization procedure. Each rabbit was injected with seminal plasma from only one donor. The injection schedule, as shown in Table 2, included intramuscular and subcutaneous injections, with and without Freund's adjuvant. The rabbits were bled 50 days following the first injection. Antisera were decanted from clotted blood and frozen and stored at $-30^{\circ} \mathrm{G}$ until use.

Immuno-electrophoresis was performed according to the micromethod of Scheidegger (1955). Microscope slides were coated with $1 \%$ agarose in a 


\section{New from Schenkman}

\section{The Psychology of Birth Planning EDWARD POHLMAN}

Discussed are these important and non-traditional questions, among many others:

What are the psychological effects of various contraceptives? ... abortion? ... sterilization?

Why do American women want children?

Do most Americans really want children?

What are the emotional and psychological costs of bearing and rearing children?

Why are many children unwanted?

What does it mean to be an 'unwanted' child?

How many unwanted children are there in America as a whole?

... among whites?... among Negroes and $/ .$. in rich and poor groups?

... among college-educated and grade-school educated families?

... among Protestants, Catholics and Jews?

What is behind the common shift from an 'unwanted' conception to a 'wanted' baby?

What are the effects of mothers' anger toward children they do not want?

How common is it for mothers to consciously want, but unconsciously reject, babies?

What is the optimum age for bearing children?

.. spacing between children? ... marriage age?

Is medical abortion dangerous physically? ... psychologically?

What special problem do poor people have in practicing contraception effectively?

What about unmarried women and contraception?

Is it ethical? ... feasible? ... common?

Does it encourage premarital sex?

What special problems do the unmarried have in contracepting?

How do various contraceptive methods, and abortion and sterilization, 'stack up' as to avoiding unwanted pregnancy, disturbing the sex relationship, affecting psychological health, and so on?

How does the sex life effect contraception? How does contraceptipn effect the sex life? Why do people go on having children when they do not want any more? What keeps them from contracepting effectively?

Can unwanted conception produce nausea and vomiting during pregnancy? ... eclampsia and pre-eclampsia? ... spontaneous abortion?

... difficulties in delivery?

Why are so many 'battered children' brought to medical attention after physical abuse from parents?

What are the effects of the population explosion?

... the economic effects?

... the psychological and spiritual effects?

What is the role of the Roman Catholic Church in contraception? What psychological factors underlie Church attitudes? What are the psychological reactions of Catholic couples to problems of contraception and unwanted children?

\section{$\$ 11.25$}

\section{SCHENKMAN PUBLISHING CO.}

ONE STORY STREET, CAMBRIDGE, MASS. 02138 , U.S.A. 
barbital buffer (ionic strength $0 \cdot 025, \mathrm{pH} 8 \cdot 2$ ). Electrophoresis was carried out at room temperature for $45 \mathrm{~min}$ at $34 \mathrm{~mA}$ and 10 volts $/ \mathrm{cm}$. After addition of antiserum, the slides were placed in a moist chamber for $24 \mathrm{hr}$ for the development of precipitin bands. They were then washed for 3 days in saline, and stained with either amidoschwartz or a triple stain composed of amidoschwartz, light green SF, and thiazine red. To facilitate comparison of the bands, each slide contained a sample of seminal plasma, antiserum made specifically against that seminal plasma, and a sample of seminal plasma from another donor.

Human blood serum was obtained from clotted blood from each of the five donors $\mathrm{A}$ to $\mathrm{E}$ and stored frozen until use. Immuno-electrophoretic studies compared each donor's seminal plasma and blood serum in separate wells on the same slide, which was developed with anti-human seminal plasma serum. Similar slides were prepared using as antiserum anti-human seminal plasma that had been absorbed by human blood serum. Absorption was accomplished by mixing equal volumes of the antiserum and blood serum, incubating the mixture for $18 \mathrm{hr}$ at $4^{\circ} \mathrm{C}$, and removing the precipitate that formed by centrifugation.

TABLE 2

INJECTION SCHEDULE FOR ANTIBODY PRODUCTION AGAINST HUMAN SEMINAL PLASMA

\begin{tabular}{l|cccccccc}
\hline & \multicolumn{10}{|c}{ Day } \\
\cline { 2 - 9 } & 1 & 5 & 8 & 12 & 15 & 35 & 39 & 46 \\
\hline $\begin{array}{c}\text { Volume seminal plasma } \\
(\mathrm{ml})\end{array}$ & 0.25 & 0.5 & 1.8 & 2.0 & 3.0 & $1.5^{*}$ & $0.5 *$ & 2.0 \\
\hline
\end{tabular}

* Intramuscular injections which included $0.5 \mathrm{ml}$ of Freund's complete adjuvant.

Concentration of seminal plasma to detect antigens present in low concentration was carried out by dialysis against dry sucrose at $4^{\circ} \mathrm{C}$. A four-fold volume decrease was achieved. Concentrated samples were compared on the same slide with untreated seminal plasma from the same individual. In order to decrease the possibility that some antigens were not being detected because the antigen-antibody concentrations were not optimal, we also carried out precipitations which utilized undiluted seminal plasma and samples of antiserum diluted through the range of $1: 1$ to $1: 16$.

Type A blood group antigens in seminal plasma were detected by utilizing the haemagglutination test of Kabat (1955). Type A red blood cells frozen in glycerol and citrate (Ghaplin, Crawford, Cutbush \& Mollison, 1954) and a commercial anti-A typing serum were employed. One volume of seminal plasma was added to 1 vol of typing serum. After incubation at room temperature for $30 \mathrm{~min}, 2$ vols of a $4 \%$ suspension of red cells were added. If the seminal plasma contained Type A agglutinogen, it inhibited the agglutination of the red cells by the typing serum. Samples of seminal plasma from Type $O$ individuals and saline substituted for either seminal plasma or typing serum served as controls. 


\section{RESULTS}

A total of nineteen antigens was demonstrated in the seminal plasmas of the eight individuals included in this study, though the seminal plasma of any single individual contained no more than sixteen antigens. Text-fig. 1 is a composite drawing, derived from experiments utilizing a number of antisera, which indicates the location and relative prominence of all antigens observed in seminal plasma in these studies. Also shown in Text-fig. 1 are the antigens detected in the blood serum of these individuals when tested against the same anti-seminal plasma antisera.
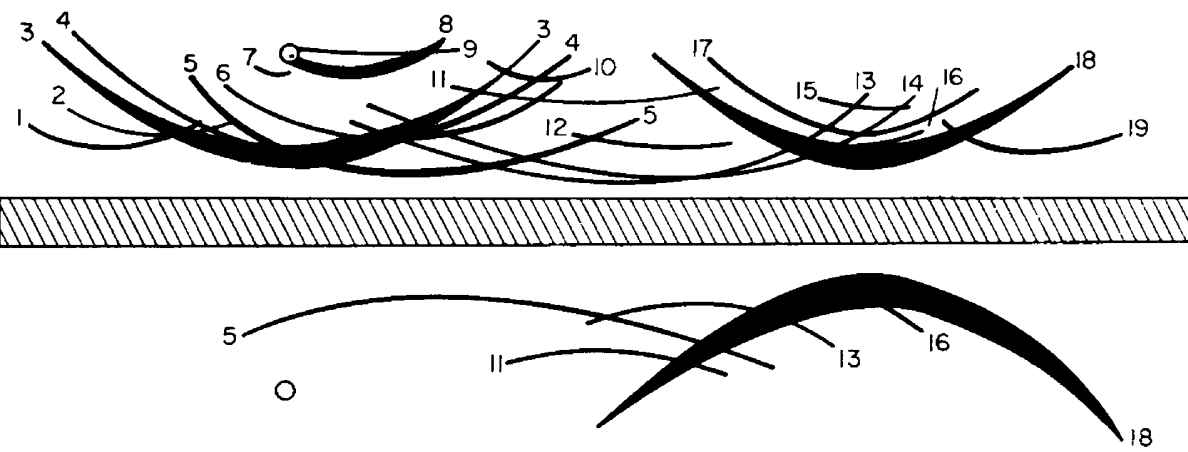

TEXT-FIG. 1. A composite diagram indicating the location and relative prominence of all antigens observed in the seminal plasma (upper antigen well) and blood serum (lower well) in these studies.

\section{TABLE 3}

ANTIGEN DETECTED IN THE SEMINAL PLASMA AND THE BLOOD SERUM OF A GROUP OF MEN

\begin{tabular}{|c|c|c|c|c|c|c|c|}
\hline Donor & $\begin{array}{l}\text { Bands not possessed } \\
\text { by this sample }\end{array}$ & $\begin{array}{c}\text { Human seminal } \\
\text { plasma-specific } \\
\text { bands }\end{array}$ & $\begin{array}{l}\text { Bands shared by } \\
\text { human serum }\end{array}$ & $\begin{array}{c}\text { Bands } \\
\text { unclassi- } \\
\text { fied as to } \\
\text { specificity }\end{array}$ & $\begin{array}{c}\text { No. of } \\
\text { antigens } \ddagger\end{array}$ & $\begin{array}{l}\text { ABO } \\
\text { blood } \\
\text { type }\end{array}$ & $\begin{array}{l}\text { Type A } \\
\text { secretor } \\
\text { status }\end{array}$ \\
\hline A & $2,7,16^{*}, 17$ & $\begin{array}{l}1,3,4,6,8,9 \\
14,15,19\end{array}$ & $\begin{array}{l}5,11,13,16 \\
18\end{array}$ & 10,12 & 15 & A & $\mathbf{S}^{+}$ \\
\hline B & $\begin{array}{l}1^{*} \dagger, 2 *, 7,10^{*} \\
15,16,17^{*}\end{array}$ & $\begin{array}{l}3,4,6,8,9 \\
14,19\end{array}$ & $\begin{array}{l}5,11,13,16 \\
18\end{array}$ & 12 & 12 & A & $\mathrm{S}^{-}$ \\
\hline C & $2,7,10,16,17$ & $\begin{array}{l}3,4,6,8,9 \\
14,15,19\end{array}$ & $\begin{array}{l}5,11,13,16 \\
18\end{array}$ & 1,12 & 14 & A & $\mathrm{S}^{-}$ \\
\hline D & $\begin{array}{l}2,4,7,10,12 \dagger \\
16,17 \dagger\end{array}$ & $\begin{array}{l}1,3,6,8,9 \\
14,15,19\end{array}$ & $\begin{array}{l}5,11,13,16 \\
18\end{array}$ & & 12 & $\mathrm{AB}$ & $\mathrm{S}^{+}$ \\
\hline $\mathrm{E}$ & $10,12,15,16,17$ & $\begin{array}{l}1,3,4,6,7,8 \\
9,14,19\end{array}$ & $\begin{array}{l}5,11,13,16 \\
18\end{array}$ & 2 & 14 & $\mathrm{O}$ & - \\
\hline$F$ & $7,15,17$ & n.a. & n.a. & n.a. & 16 & A & $\mathrm{S}^{+}$ \\
\hline G & $2,4,7,15,16$ & n.a. & n.a. & n.a. & 14 & $\mathrm{O}$ & - \\
\hline $\mathrm{H}$ & $2,4,7,15,16,17$ & n.a. & n.a. & n.a. & 13 & $\mathrm{AB}$ & $\mathrm{S}^{+}$ \\
\hline
\end{tabular}

n.a. = Data not available.

* Bands not appearing in the human seminal plasma sample but which have stimulated antibody production when the sample was used for inoculation.

+ Band appears only when concentrated sample is used.

$\$$ Includes only those apparent in unconcentrated sample. 
As shown in Table 3, the number of antigens detected in the seminal plasma of each donor included in this study range from twelve to sixteen. The antigens are identified in Table 3 according to the numbering system used in Text-fig. 1 . Bands 3, 5, 6, 8, 9, 11, 13, 14, 18 and 19 appeared in the seminal plasma of all subjects tested. In certain instances, indicated in Table 3, more antigens could be detected when the seminal plasma was concentrated. In other instances, the seminal plasma of a donor induced formation of an antibody against an antigen which could not be detected in the seminal plasma of that donor. For example, the antiserum produced by seminal plasma from Donor B, when tested against seminal plasma from some other donors, resulted in the appearance of Bands 1, 2, 10 and 17, though these bands did not appear when this antiserum was tested against seminal plasma from Donor B (Text-fig. 2). When the seminal plasma of Donor B was concentrated, Band I was detected, but no further evidence of the presence of Bands 2, 10 and 17 was obtained. The
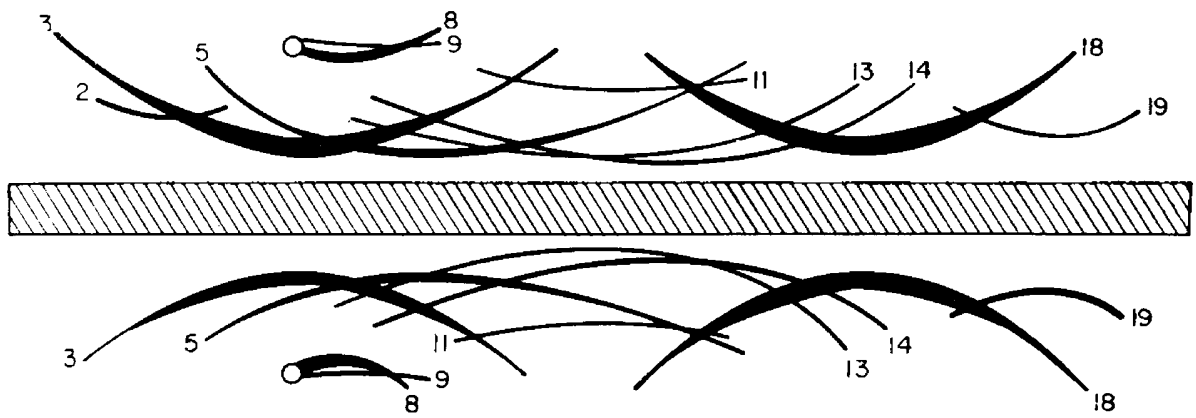

TEXT-FIG. 2. A diagram of the bands appearing when antiserum against the seminal plasma of Donor B was tested against seminal plasma from Donor E (upper well) and Donor B (lower well). Though seminal plasma from Donor B elicited the production of antibody against antigen 2 the existence of this antibody could be detected only by testing against seminal plasma of another donor, since the band was not detectable in the seminal plasma of Donor B. All of the antigens belonging to the samples are not shown.

utilization of diluted antiserum in an attempt to provide optimal antigenantibody concentration did not reveal the presence of any more antigens.

In order to determine whether the variations observed were of seminal plasma-specific antigens or those present in blood serum as well, we tested blood serum obtained from Donors A to $\mathrm{E}$ against anti-seminal plasma sera. Five bands were detected in the serum of all donors tested. Dilutions of this serum ranging from $1: 1$ to $1: 10$ revealed no other antigens. On the basis of their immuno-electrophoretic characteristics, these antigens were identified as Bands 5, 11, 13,16 and 18. Band 16, which appeared in the serum of all donors tested, appeared in the seminal plasma of Donor $F$ only. The antiserum in which the corresponding antibody occurred, however, was produced by immunizing with seminal plasma of Donor A.

The use of anti-seminal plasma serum from which antibodies to blood serum proteins had been absorbed confirmed the identification of the serum protein bands in seminal plasma. Bands 3, 6, 8, 9, 14 and 19, which appear to be seminal plasma specific antigens, occurred in the seminal plasma of all in- 
dividuals tested (Text-fig. 3). In addition, some seminal plasma-specific antigens were only detected in the seminal plasma of some donors (Table 3 ). Because they appeared neither in the blood serum nor in the reaction between seminal plasma and antiserum absorbed with seminal plasma, it was not possible to determine the specificity of Bands 1, 2, 10 and 12 .

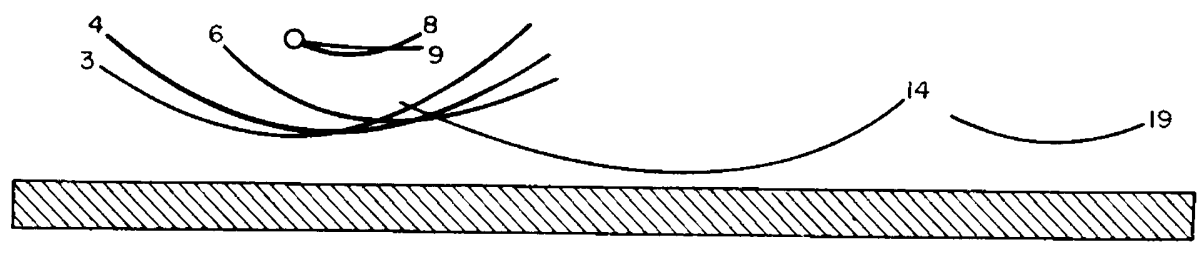

0

Text-FIG. 3. A diagram of the bands appearing when human seminal plasma was tested against antiserum to human seminal plasma which had been absorbed with blood serum from the donor who provided the seminal plasma (upper well). The completeness of absorption is indicated by the absence of bands when the absorbed antiserum was tested against blood serum (lower well).

The possibility that one of the antigens could be identified as the Type A blood group substance was investigated by determining whether or not any antigen appeared regularly only in the seminal plasma of those men, identified in Table 3, who were Type A secretors. Since no correlation existed between the Type A secretors and the appearance of any single antigen, it appears that none of the antibodies produced was against Group A substance.

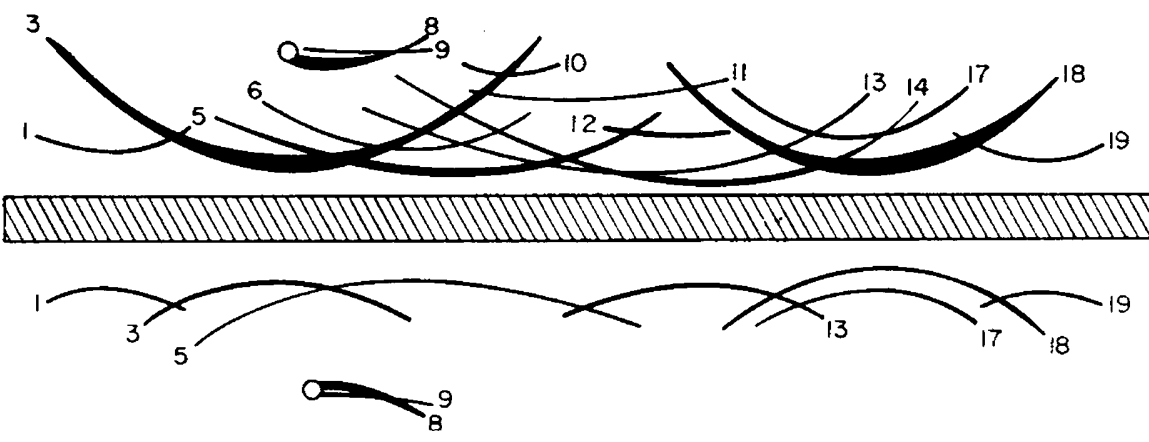

TEXT-FIG. 4. A diagram of the bands appearing in the seminal plasma of Donor G. Upper well: whole ejaculate. Lower well: sample in which the first part of the ejaculate was lost during the collection procedure.

The difference in the antigens appearing in three ejaculates obtained within $\frac{1}{2}$ to $2 \mathrm{hr}$ and of a fourth ejaculate obtained 2 weeks later was investigated in Donors $F, G$ and $H$. No change in the antigens detected was observed as a result of repeated ejaculation. However, the first part of the first ejaculate submitted by Donor G was lost during collection, and, as shown in Text-fig. 4, fewer bands appear, and some of the bands appear to be markedly reduced in intensity in that sample. 
It seemed possible that some of the antigens detected in seminal plasma in the study occurred because of the partial breakdown 'during preparation and storage' of other proteins. In an attempt to detect such changes, two additional ejaculates were obtained from Donor F. Seminal plasma from one sample was prepared in the same manner as previous samples, then stored at $4^{\circ} \mathrm{C}$ for $12 \mathrm{hr}$, and then stored at $-30^{\circ} \mathrm{G}$ for 2 weeks. The second ejaculate was refrigerated immediately after ejaculation and, without being frozen, was subjected to immuno-electrophoresis within $90 \mathrm{~min}$ after collection. A part of this latter sample was frozen briefly, thawed, and then subjected to immuno-electrophoresis. These samples, and one prepared in the usual manner which had been stored at $-30^{\circ} \mathrm{C}$ for 8 months, provided a series in which we could evaluate any changes which occurred because of freezing and storage. All of the samples in this series showed identical electrophoretic patterns, indicating that the results of this study were probably not influenced by storage artifacts. However, protein changes which occurred because of protenlysis before immuno-electrophoresis could not be evaluated because of the time necessary for sample preparation.

\section{DISCUSSION}

The purpose of the present experiments was to examine the hypothesis that the seminal plasma of all members of the same species is antigenically identical. The data indicate that most antigens, especially those that exhibit the greatest antigenicity, occurred in the seminal plasma of all subjects studied. Subjectively the experimenter is impressed with the similarities from individual to individual, rather than the relatively minor differences. Yet enough variation appears in seminal plasma from the few individuals studied to suggest that examination of a larger series of men would demonstrate even greater variation. While one cannot exclude the possibility that the differences which we observed are due to the concentration of certain antigens being below levels detectable by immuno-electrophoresis, the hypothesis of the antigenic identity of seminal plasma of different individuals of the same species cannot be confirmed. Although the tolerance of the female to the major antigenic components of seminal plasma may be explained by assuming a similarity among all males, an alternative explanation must be sought for the immunological inertness of the female to the minor differences among males.

Further experiments will be required to elucidate the physiological mechanism by which the female avoids the immunological consequences of repeated exposure to these minor antigens. It may be that the antigenicity of these components under experimental conditions is exaggerated beyond that which would exist in nature. The enzymes secreted into the female reproductive tract or the proteolytic enzymes in seminal plasma may serve to degrade the seminal plasma antigens so that their relatively low antigenicity is further reduced or eliminated. Also, it is possible that the sperm-agglutinating antibodies in blood (Nakabayashi, Tyler \& Tyler, 1961; Franklin \& Dukes, 1964) and antibodies in cervical mucus (Parish, Garron-Brown \& Richards, 1967) which are cytotoxic to spermatozoa may be related to sperm-coating substances in the seminal 
plasma (Weil, 1967), and that this is in fact a physiological manifestation of sensitization to seminal plasma. Finally, it is possible that while certain antigens are lacking in the seminal plasma of certain males, all individuals are immunologically tolerant to all of the antigens which occur in all seminal plasmas because such antigens occur elsewhere in the organism. Some support for this latter possibility may be derived from the Type A blood group substance, even though all individuals in the species are not tolerant to Type A blood group substance, nor was it one of the antigens in these experiments. It serves as an analogy, however, in that both secretors and non-secretors would be tolerant to the antigen, but it would appear in the seminal plasma of secretors only (Edwards, Ferguson \& Coombs, 1964).

The present discussion has been based upon the assumption that seminal plasma is not antigenic to females of the same species, as indicated by the experiments of Menzoian \& Ketchel (1966) and by the rarity with which sensitization to seminal plasma proteins is seen as a clinical problem (Halpern et al., 1967). These data should not be directly compared with reports of the iso-antigenicity of seminal plasma (Weil \& Roberts, 1965; Shulman, Riera \& Yantorno, 1968) which have invariably utilized Freund's adjuvant in the injection procedure, since the ability of Freund's adjuvant to sensitize an individual even to his own protein is well known.

Differences in the antigenicity of components of seminal plasma from different males have been reported by Searcy, Craig \& Bergquist (1964) and Weil \& Roberts (1965). However, these investigators worked with no more than the fifteen or fewer antigens detected by other workers (Rao \& Sadri, 1959; Mischler \& Reineke, 1966; Behrman \& Amano, 1967) while the present experiments extended the number of antigens to nineteen. The increase in the number of antigens we detected may be related to our practice of injecting each rabbit with seminal plasma from a single man, in contrast to the practice of the previously mentioned workers who used pooled samples either for the production of antibodies or for the immuno-electrophoretic analysis itself. It is quite likely that minor components present in the seminal plasma of only one donor to the pool would be rendered undetectable by the dilution effect of pooling.

Due to technical difficulties associated with the complexity of the immunoelectrophoretic pattern obtained with seminal plasma, it was not possible to demonstrate reactions of identity (fusion of precipitin bands) between the antigens of seminal plasma and the antigens of blood serum. The assignment of numbers identifying these bands is based on less reliable means. However, it appears that the major differences in the seminal plasma from different men is attributable to these antigens that are specific to the seminal plasma.

\section{ACKNOWLEDGMENTS}

This research was supported by Public Health Service Grant HD-01945.

\section{REFERENCES}

Behrman, S. J. \& Amano, Y. (1967) Immunochemical studies on human seminal plasma. I. Antigenicity of seminal protein. Int. F. Fert. 12, 291. 
Chaplin, H., Crawford, H., Gutbush, M. \& Mollison, P. L. (1954) Post-transfusion survival of red cells stored at $-20^{\circ} \mathrm{C}$. Lancet, i, 852.

Edwards, R. G., Ferguson, L. G. \& Coombs, R. R. A. (1964) Blood group antigens on human spermatozoa. F. Reprod. Fert. 7, 153.

FrankeIn, R. R. \& Dukes, C. D. (1964) Further studies on spermagglutinating antibody and un explained infertility. 7. Am. med. Ass. 190, 682 .

Halpern, B. N., Ky, T. \& Robert, B. (1967) Clinical and immunological study of an exceptional case of reaginic type sensitization to human seminal fluid. Immunology, 12, 247.

Hermann, G., Licht, W., Keutel, H. J. \& KRUg, E. (1958) Electrophoretische Untersuchungen am menschlichen Spermaplasma. Z. ges. exp. Med. 130, 436.

KabAt, E. A. (1955) Blood group substances, p. 56. Academic Press, New York.

Menzoian, J. O. \& Ketchel, M. M. (1966) Immunological tolerance of the female to homologous seminal plasma protein. Nature, Lond. 211, 133.

Mischler, T. W. \& Reineke, E. P. (1966) Some electrophoretic and immunological properties of human semen. 7. Reprod. Fert. 12, 125.

Nakabayashi, N. T., Tyler, E. T. \& Tyler, A. (1961) Immunologic aspects of human infertility. Fert. Steril. 12, 544.

Parish, W. E., Carron-Brown, J. A. \& Richards, C. B. (1967) The detection of antibodies to spermatozoa and to blood group antigens in cervical mucus. $\mathcal{F}$. Reprod. Fert. 13, 469.

RAO, S. S. \& SADRr, K. K. (1959) Immunological studies with human semen and cervical mucus. VIth International Conference on Planned Parenthood, New Delhi, p. 313.

Scheloegger, J. J. (1955) Une micro-méthode de l'immuno-électrophorèse. Int. Archs Allergy appl. Immun. 7, 103.

Searcy, D. L., Craig, R. G. \& Bergquist, L. M. (1964) Immunochemical properties of normal and pathologic seminal plasma. Fert. Steril. 15, 1.

Shulman, S., Riera, C. \& Yantorno, C. (1968) Studies on organ specificity. XIX. Antigenic specificity of seminal plasma and the formation of autoantibodies. F. Immun. 100, 682.

WeIL, A. J. (1967) Antigens of the seminal plasma. J. Reprod. Fert., Suppl. 2, 25.

Weit, A. J., Korsevalov, O. \& Wilson, L. (1956) Antigens of human seminal plasma. Proc. Soc. exp. Biol. Med. 92, 606.

WeIL, A. J. \& Roberts, C. O. (1965) Fertility of female rabbits after isoimmunization with seminal plasma. Fert. Steril. 16, 356. 